\title{
Tailoring Soft Local Zones in Quenched Blanks of the Steel 22MnB5 by Partial Pre-cooling with Compressed Air
}

\author{
Oleksandr Golovko, Max-Henry Stolte, Kai Wölki, Sven Hübner, Bernd-Arno Behrens, Hans Jürgen Maier, and Florian Nürnberger
}

(Submitted April 15, 2020; in revised form June 2, 2020; published online July 1, 2020)

\begin{abstract}
The high-strength boron steel $22 \mathrm{MnB5}$ steel is widely used for automotive lightweight constructions. A novel approach is promising to tailor strength and ductility in the hardened condition using locally pretempered sheets for the hot stamping process. It results in the formation of locally soft spots where mechanical joining is subsequently intended. A slow pre-cooling of the later joining zones with cooling rates below a certain critical cooling rate for obtaining a decreased strength in these regions is required. A tubular air cooling system suited for this task is presented and tested in a process where the subsequent quenching of the overall sheet is realized by rapid cooling in a water bath. Varying the air pressure and cooling duration allows controlling the size of the softened local spot in a wide range and still obtaining a bainitic microstructure. Using two-stage cooling with point jet nozzles and a subsequent hot stamping process with water-cooled dies resulted in a main sheet hardness of about $470 \mathrm{HV} 5$ and of $260 \mathrm{HV} 5$ in the pre-cooled spots, respectively.
\end{abstract}

Keywords process-integrated heat treatment, air pre-cooling, press hardening

\section{Introduction}

High-strength steels are of great interest for automotive lightweight constructions as these allow employing sheets with reduced thickness (Ref 1-3). A further efficiency increase can be realized by the application of tailored tempering (Ref 4-6). In this concept, high-strength sections are combined with ductile sections in one single structural part. Hence, such parts feature both sections suited for mechanical joining operations as well as high-strength areas needed to improve the safety of the vehicles. In the same context, material zones with a locally reduced strength and increased ductility can be used to increase the energy absorption capacity and thus crash performance (Ref 7-11).

Several technologies are available to obtain tailored properties in combination with hot stamping (cf. Table 1):

Oleksandr Golovko, Max-Henry Stolte, Hans Jürgen Maier, and Florian Nürnberger, Institut für Werkstoffkunde (Materials Science), Leibniz Universität Hannover, An der Universität 2, 30823 Garbsen, Germany; and Kai Wölki, Sven Hübner, and Bernd-Arno Behrens, Institut für Umformtechnik und Umformmaschinen (Institute of Forming Technology and Machines), Leibniz Universität Hannover, An der Universität 2, 30823 Garbsen, Germany. Contact e-mails: golovko@iw.uni-hannover.de, woelki@ifum.uni-hannover.de, behrens@ifum.uni-hannover.de, nuernberger@iw.uni-hannover.de. huebner@ifum.uni-hannover.de, maier@iw.uni-hannover.de, and
- One approach uses partial heating limited to certain sections of the blanks prior to the hot stamping. The later soft zones have to be kept below the $A \mathrm{c}_{1}$-temperature in order to prevent microstructural transformations into austenite and retain the initial soft ferritic-perlitic microstructure (Ref 12-14). In contrast, the sections that are to be hardened have to be heated above the $A c_{3}$-temperature in order to generate a fully martensitic microstructure during the quenching while hot stamping with water-cooled tools. For such routes, furnaces with different independently controlled heating zones are required featuring a ceramic brick insulation between each heating zone (Ref 15). One disadvantage of this method is high energy expenses (Ref 16). Furthermore, it is possible to use alternative heating processes that ensure high heating rates and low oxidation, such as inductive (Ref 17, 18), conductive (Ref 18, 19) and contact (Ref 20, 21) heating. However, these might be disadvantageous due to extensive equipment, non-uniformity of heating or the necessity to use uncoated sheets.

- Partial properties after press hardening can be realized using tailored pre-cooling in a multizone tempering station after heating in common roller heard furnace (Ref 22, 23). The tempering station holds a section of the blank in the austenitized state before press hardening using burners as well as induction, conduction or contact heating. Other sections of the blank are cooled to obtain a bainitic structure. A novel variation of such approach is developed in the present work.

- Common alternative approaches apply differing cooling conditions to homogenously austenitized blanks during hot stamping. Examples are partially heated tools, tools with sections of differing thermal properties or the die relief method (Ref 1, 16, 24, 25). In all cases a complex tool design results.

- The application of differing cooling conditions using early extraction in a hot stamping process was proposed in Die- 


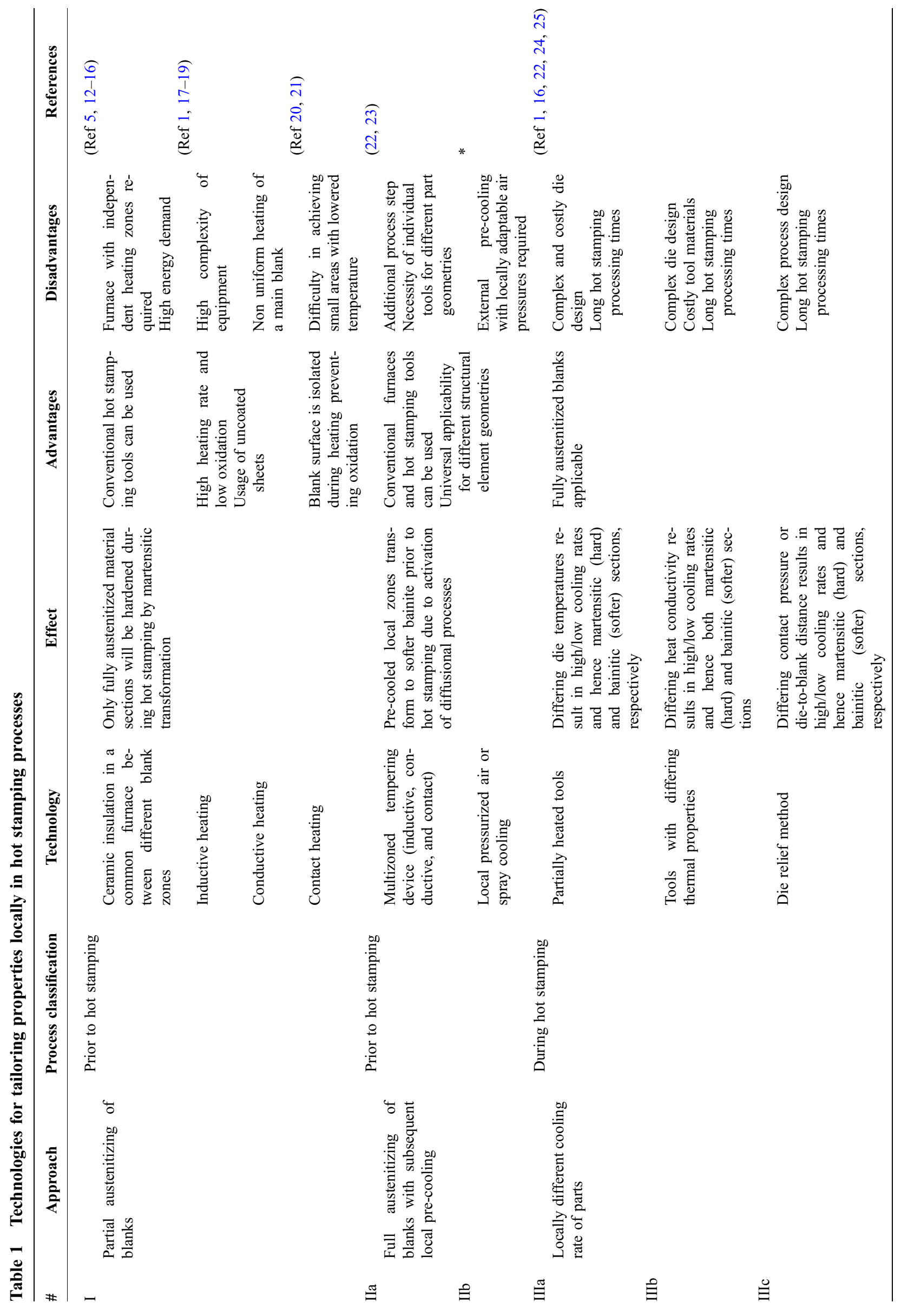


kamp et al. (Ref 26, 27). In this approach of partial quenching, blanks are fully austenitized in a furnace, hot stamped with a reduced holding time of only $0.6 \mathrm{~s}$ and subsequently locally cooled with a water-air spray. Due to the locally adapted heat transfer conditions, hardened martensitic sections as well as softer bainitic ones can be achieved. Suited extraction temperature of the parts from the hot stamping press was in the range of $450-530^{\circ} \mathrm{C}$. Cooling rates of about $64 \mathrm{~K} / \mathrm{s}$ in hard zones and $2 \mathrm{~K} / \mathrm{s}$ in soft zones allowed to realize a Vickers hardness difference up to 200 HV10.

- Alternatively, a partially tempering of the fully hardened parts after hot stamping can be applied though this requires an additional subsequent processing step (Ref 28).

Since these technologies rely either on a complex furnace design, long processing times during hot stamping or further additional subsequent processing steps, alternative approaches are of significant interest. In the present study, local pre-cooling of fully austenitized blanks prior to the hot stamping was employed, since conventional furnaces and heating strategies for the full austenitization can be applied and no modifications of the hot stamping tools are required. In the proposed approach (cf. Table 1, approach II), sections of reduced hardness are realized by local pre-cooling to intermediate temperatures prior to the hot stamping to allow diffusional processes to take place, and thus prematurely form bainite instead of martensite during the actual hot stamping (s. Fig. 1). Compared to approach IIId (cf. Table 1), a negligible residual distortion of the hot stamped parts can be expected. Using the example of the boron-alloyed steel 22MnB5 (1.5528), the intention was to realize softened sections with a large difference in hardness as compared to the martensitic matrix. Compressed air was used to pre-cool these sections prior to the hot stamping and thus promote a bainitic transformation. In order to reduce the experimental effort, the final cooling of the blanks was carried out by water quenching in most of the experiments. For selected cases, an industrial press with a water-cooled tool was employed in order to evaluate the transfer potential of the proposed approach with respect to actual application.

\section{Material Properties}

The boron-alloyed steel 22MnB5 (1.5528) was used in the form of blanks with a sheet thickness of $1.5 \mathrm{~mm}$. The actual chemical composition is provided in Table 2 and was determined using an optical emission spectrometer (SPECTROMAXx LMX06). In order to prevent scaling due to hightemperature oxidation in the furnace and provide a protection against corrosion, the sheets are coated with an Al-Si layer, which obtains its final properties due to diffusional processes during heating and holding in the furnace.

The as-received sheets featured a ferritic-perlitic structure with mechanical properties summarized in Table 3. The dependence of the properties with respect to the direction relative to the rolling axis was found to be low with variations of no more than $2 \%$ for the strength characteristics and up to $3 \%$ for the ductility. 


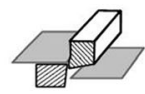

cutting

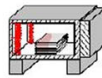

heating

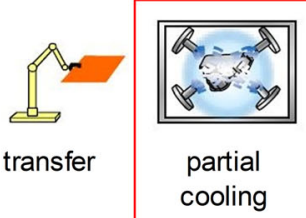

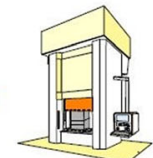

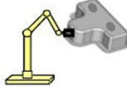

deep drawing transfer final cooling

Fig. 1 Proposed process chain featuring a local pre-cooling prior to the hot stamping to create soft bainitic microstructures

Table 2 Nominal and measured chemical composition of the initial sheets, wt.\%

\begin{tabular}{|c|c|c|c|c|c|c|c|c|c|c|}
\hline Element & $\mathrm{Fe}$ & C & $\mathbf{S i}$ & Mn & $\mathbf{P}$ & $\mathbf{S}$ & Al & $\mathrm{Cr}$ & $\mathbf{T i}$ & B \\
\hline Nominal (29) & Bal. & $0.19-0.25$ & $\leq 0.40$ & $1.1-1.4$ & $\leq 0.0245$ & $\leq 0.015$ & $0.02-0.06$ & $0.15-0.35$ & $0.02-0.05$ & $0.0008-0.005$ \\
\hline Measured & 97.88 & 0.233 & 0.268 & 1.18 & 0.011 & 0.002 & 0.038 & 0.18 & 0.031 & 0.0039 \\
\hline
\end{tabular}

Table 3 Mechanical properties of blanks in the initial condition, measured using tensile samples according to DIN $50125-H 12.5 \times 50$

\begin{tabular}{lccc}
\hline Direction & Ultimate tensile strength, MPa & $\mathbf{0 . 2 \%}$ offset yield stress, MPa & Total elongation at fracture, \% \\
\hline Lengthwise & 611 & 386 & 22.3 \\
Crosswise & 619 & 394 & 22.1 \\
$45^{\circ}$ & 609 & 395 & 22.8 \\
\hline
\end{tabular}

\section{Methods}

\subsection{Layout of the Blank with Pre-cooled Sections}

The sheets used featured a size of $200 \mathrm{~mm} \times 260 \mathrm{~mm}$. Softened sections were chosen to be separated 84 and $200 \mathrm{~mm}$ from each other. As marked in Fig. 2, the temperature-time profile was recorded at the four selected positions no. 1-4 during heating and at the positions no. 3 and 4 during cooling. Temperature was measured with $\mathrm{Ni}-\mathrm{NiCr}$ thermocouples that were spot-welded to the blank surface.

\subsection{Local Pre-cooling}

The developed tubular cooling device for the local precooling of the sheets by compressed air is depicted in Fig. 3. The cooling air is fed through an inner cooper tube with an inside diameter of $5 \mathrm{~mm}$. A small point jet nozzle LUVS201295-18, Fa. "Spraying Systems," was mounted optionally to the outlet of the inner tube. This nozzle is characterized with one central hole and six peripherally guiding holes. The air heated up by the hot sheet is exhausted through the outer tube (Fig. 3, left), which had an inside diameter of $16 \mathrm{~mm}$. In order to minimize air leakage, a spring mounted foot cap was used at the bottom of each outer tube. The tube sets were arranged in a pneumatically driven rectangular frame with a thermally insulated plate at the bottom (steel covered with an insulating layer). An electrically heated stainless-steel plate, which is referred to as the "temperature control plate," is positioned at the bottom of the housing featuring a maximal possible temperature of $850{ }^{\circ} \mathrm{C}$.

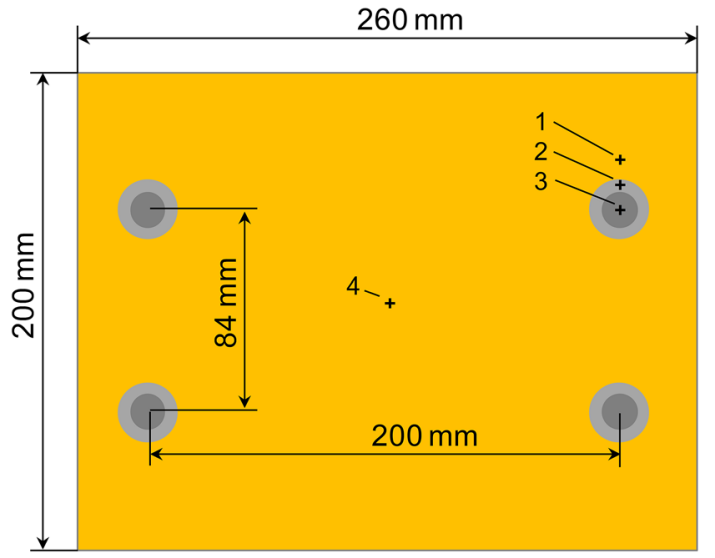

Fig. 2 Layout of softened sections on the processed blank (1: nonpre-cooled position close to a pre-cooling spot; 2 : transition zone; 3 : center of pre-cooled section; 4: non-pre-cooled position in the center of the sheet)

\subsection{Austenitization Prior to Pre-cooling}

In order to be fully austenitized, the steel $22 \mathrm{MnB} 5$ is normally exposed to a furnace temperature of $850-950{ }^{\circ} \mathrm{C}$ with a dwell time between 3 and 6 min (Ref 1, 30). In the present study, the furnace temperature was increased to $1050{ }^{\circ} \mathrm{C}$ in order to ensure a sheet temperature of $870-900{ }^{\circ} \mathrm{C}$ prior to quenching regarding a possible heat loss not only in the later pre-cooled sheet sections (desired) but in the non-pre-cooled areas as well (non-desired). Total time of heating and holding 

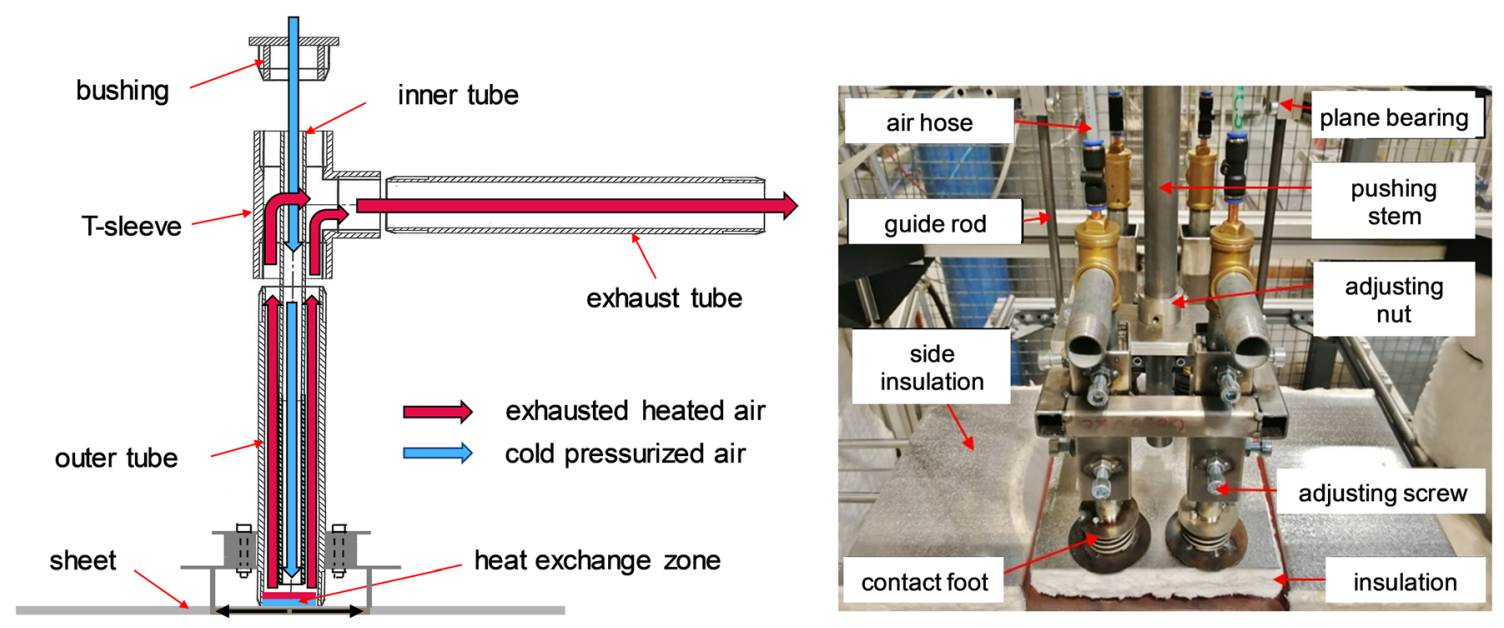

Fig. 3 Schematic showing the tubular cooling device (left) and actual setup (right)

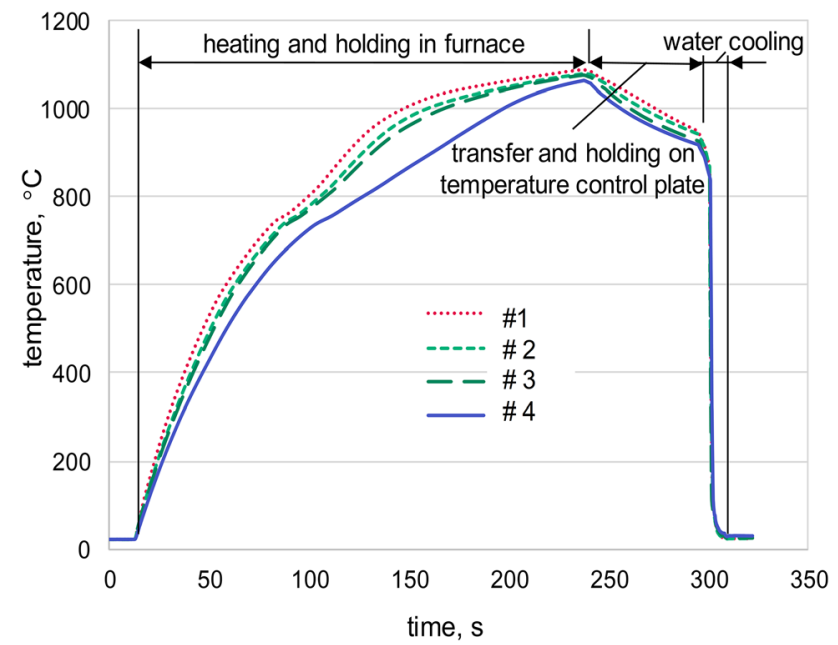

Fig. 4 Representative temperature-time profile at the control points (Pos. 1-4, cf. Fig. 2) during heating, transfer and final water quenching

was set to $4 \mathrm{~min}$. The resulting temperature-time profiles for the selected control points are shown in Fig. 4.

\subsection{Air-Cooling Conditions}

To evaluate the characteristics of the pre-cooling by compressed air, furnace-heated sheets were transferred in a thermally insulated container to the temperature control plate, which was heated to $800{ }^{\circ} \mathrm{C}$. Then, the frame with the tubular cooling devices was clamped to the hot sheets and the compressed air fed to the tubes for cooling. The distance of the outlet of the inner tube to the sheet surface was varied from 5 to $20 \mathrm{~mm}$. In these experiments, the air pressure was varied from 0.1 to $0.4 \mathrm{MPa}$ with a constant cooling time of $40 \mathrm{~s}$. The air flow rate reached the nominal values within approx. $2 \mathrm{~s}$. For this setup, the flow rate $w$ in $1 / \mathrm{min}$ depends linearly on the nominal air pressure $p$ in $\mathrm{MPa}$ :

$w=23+353 \cdot p$

After pre-cooling with compressed air, the samples were transferred to the water bath within $3 \mathrm{~s}$ and quenched. Based on the data from the experiments with pre-cooling for $40 \mathrm{~s}$, cooling conditions were varied in an attempt to reduce the overall cooling time (cf. Table 4). Provided that the bainitic transformation can be activated quickly in a first cooling step, more rapid quenching can be applied in the second. In such a way, the total processing time can be shortened.

\subsection{Microstructure Adapted Local Cooling Strategy}

According to the proposed approach, the cooling of the samples was carried out in several stages. After furnace heating, the samples were slowly air cooled in one or two steps at the designated four positions with cooling rates of no more than the critical cooling rate of $27 \mathrm{~K} / \mathrm{s}$ to prevent a premature transformation to martensite (Ref 1$)$. At the end of this slow cooling, the temperature at the air-cooled points had to meet the one for the bainitic regime as given by the time-temperature-transformation diagram (cf. Fig. 5) with temperatures ranging from 400 to $600{ }^{\circ} \mathrm{C}$. The cooling curve for the soft zones is schematically depicted by the line marked 1. At the same time, the material sample sections which are to be hardened by later quenching had to be held at a temperature above $A \mathrm{c}_{3}$ (line 2 in Fig. 5). In the final stage, the samples were rapidly cooled by water quenching so that the non-pre-cooled material sections transformed a fully martensitic microstructure.

The final experimental series of hot stamping was carried out using an industrial press (Dunkes HD250) with water cooled tools instead of water bath quenching as the last operation of processing. Total time of the hot stamping was $8 \mathrm{~s}$.

\subsection{Specimen Preparation and Characterization}

After the experiments, two types of specimens were used to measure the Vickers hardness and to characterize the microstructure $(44 \mathrm{~mm} \times 15 \mathrm{~mm})$ as well as to prepare tensile test specimen $(12.5 \mathrm{~mm} \times 30 \mathrm{~mm})$. For the latter, the circular pre-cooled section was in the center of the gauge length. The Vickers hardness test was conducted with a force of $49 \mathrm{~N}$ (HV5). For every parameter combination, 5 specimens were tested with about 90 indentations along the center line of the sheets' cross section. Some of the specimens that were used for the micro-hardness testing were subsequently etched in a solution of $2 \% \mathrm{HNO}_{3}$ to reveal the microstructure by light optical microscopy (Leica DM 400). 


\section{Results and Discussion}

\subsection{Cooling Rates and Holding Temperatures}

A typical temperature profile for the entire process is depicted in Fig. 6. Extraction of the hot sheets from the furnace, transfer in a thermally insulated container and placing them onto the temperature control plate takes about $10 \mathrm{~s}$. Thus, the sheet temperature when starting the pre-cooling by compressed air is in the range of $970-1000{ }^{\circ} \mathrm{C}$. After the first $10 \mathrm{~s}$ of air cooling, the temperature drops down to $700{ }^{\circ} \mathrm{C}$ for a pressure of $0.1 \mathrm{MPa}$ and to about $520^{\circ} \mathrm{C}$ at $0.4 \mathrm{MPa}$. The greater the air pressure, the lower the difference between the cooling curves at the different pressures. The end temperature after this cooling stage in the center of the pre-cooled zone (point 3 in Fig. 2) ranged from 330 to $505{ }^{\circ} \mathrm{C}$, and thus mean cooling rates were between 12 to $16 \mathrm{~K} / \mathrm{s}$ (s. Table 5). Transferring the sheets for water quenching took 5-7 s, and from Fig. 6 the temperature increase is about $80-90{ }^{\circ} \mathrm{C}$ with reheating rates of $12-16 \mathrm{~K} / \mathrm{s}$. This reheating is caused by the heat transfer from the inside of the sheets towards the surface as well as from the non-cooled material areas to those which were pre-cooled.

\subsection{Mechanical Properties}

The tensile test results of a set of specimens taken from softened air pre-cooled zones are summarized in Table 6. The differences in the ultimate tensile strength of samples cooled at air pressures of $0.2 \mathrm{MPa}$ and above are marginal. The yield strength is more sensitive to the air pressure: it changes from approx. $700 \mathrm{MPa}$ for samples treated with $0.1 \mathrm{MPa}$ up to about $900 \mathrm{MPa}$ with 0.4 MPa. This is in accordance with data of (Ref 31) where the authors obtained tensile strength values of $800 \mathrm{MPa}$ (cooling rate not specified). In another work, Güler et al. (Ref 32) reported tensile strength values of $757 \mathrm{MPa}$ for sheets with a thickness of $1.7 \mathrm{~mm}$ after cooling from $950{ }^{\circ} \mathrm{C}$ in still air.
Though decreasing values of total elongation at fracture with increasing air pressure were observed, the values of the total elongation are not given in Table 6 since the tensile specimens featured a non-homogenous microstructure distribution and the chosen test geometry did not conform to the standard. Instead, the Vickers hardness was measured across the pre-cooled zones.

\subsection{Microstructure and Hardness Distribution Upon Pre-cooling with $0.1 \mathrm{MPa}$}

The typical distribution of the hardness in the pre-cooled area is depicted in Fig. 7 (cooling time $40 \mathrm{~s}$; tube-to-sheet distance $5 \mathrm{~mm}$ ). The upper green line gives reference values of the non-pre-cooled sheet section with values of about 500 HV5. As intended, a significant hardness reduction in the pre-cooled zones could be realized; the hardness data show a good reproducibility for different samples. With values of 250-300 HV5, the Vickers hardness in the softened zone corresponds to

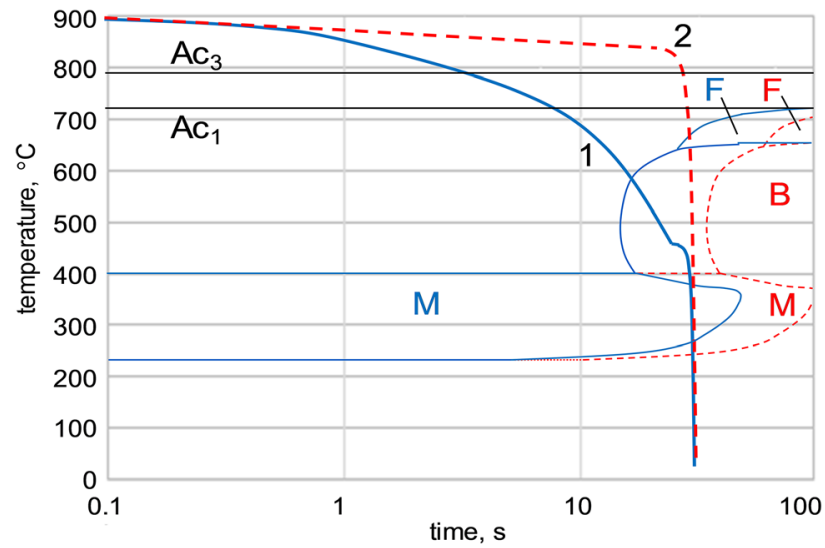

Fig. 5 Time-temperature-transformation (TTT) diagram and proposed cooling regime in "soft" (1) and "hard" (2) zones

Table 4 Cooling conditions used in the experiments

\begin{tabular}{|c|c|c|c|c|c|c|c|c|c|}
\hline \multirow[b]{3}{*}{$\#$} & \multicolumn{8}{|c|}{ Air pre-cooling } & \multirow[b]{3}{*}{$\begin{array}{c}\text { Type of final } \\
\text { cooling }\end{array}$} \\
\hline & \multirow[b]{2}{*}{$\begin{array}{l}\text { Nozzle } \\
\text { type* }\end{array}$} & \multirow[b]{2}{*}{$\begin{array}{c}\text { Cooling } \\
\text { distance, } \mathbf{m m}\end{array}$} & \multicolumn{3}{|c|}{ Initial step } & \multicolumn{3}{|c|}{ Second step } & \\
\hline & & & $\begin{array}{c}\text { Air pressure, } \\
\text { MPa }\end{array}$ & $\begin{array}{c}\text { Flow rate, } \\
\text { l/min }\end{array}$ & $\begin{array}{c}\text { Duration, } \\
\mathbf{s}\end{array}$ & $\begin{array}{c}\text { Air pressure, } \\
\text { MPa }\end{array}$ & $\begin{array}{c}\text { Flow rate, } \\
\text { l/min }\end{array}$ & $\begin{array}{c}\text { Duration, } \\
\mathbf{s}\end{array}$ & \\
\hline 1 & IT & 5 & 0.1 & 58 & 40 & - & - & - & \multirow[t]{10}{*}{ Water bath } \\
\hline 2 & IT & 5 & 0.2 & 94 & 40 & - & - & - & \\
\hline 3 & IT & 5 & 0.3 & 129 & 40 & - & - & - & \\
\hline 4 & IT & 5 & 0.4 & 164 & 40 & - & - & - & \\
\hline 5 & IT & 10 & 0.2 & 94 & 40 & - & - & - & \\
\hline 6 & IT & 20 & 0.2 & 94 & 40 & - & - & - & \\
\hline 7 & IT & 10 & 0.2 & 94 & 30 & - & - & - & \\
\hline 8 & IT & 10 & 0.05 & 38 & 10 & 0.1 & 58 & 10 & \\
\hline 9 & IT & 10 & 0.05 & 38 & 15 & 0.1 & 58 & 10 & \\
\hline 10 & IT & 10 & 0.05 & 38 & 15 & 0.1 & 58 & 15 & \\
\hline 11 & IT & 10 & 0.05 & 38 & 15 & 0.1 & 58 & 10 & \multirow[t]{4}{*}{ Water cooled tool } \\
\hline 12 & IT & 10 & 0.05 & 38 & 15 & 0.1 & 58 & 15 & \\
\hline 13 & PJ & 10 & 0.05 & 38 & 15 & 0.1 & 58 & 10 & \\
\hline 14 & PJ & 10 & 0.05 & 38 & 15 & 0.1 & 58 & 15 & \\
\hline
\end{tabular}


a bainitic microstructure. The diameter of the softened zone is slightly greater than the inner diameter of the outer tube. This can be explained by two effects: heat transfer between precooled and untreated zones and heat transfer due to direct contact with the outer exhaust tube (steel tube with wall thickness $1.8 \mathrm{~mm}$ ).

The microstructures in the key areas featuring the different hardness values are displayed in Fig. 8. The non-pre-cooled sheet sections from the center of the blank (pos. " $d$ " in Fig. 7) show a fully martensitic microstructure (brown). Areas with the lowest hardness (pos. " $a$ ") and in the center of pre-cooled zone (pos. " $b$ ") are bainitic (grey) with only small fractions of martensite. The transition area (pos. "c") is characterized by a mixed microstructure and hardness values of $400 \mathrm{HV} 5$ where the amount of martensite is in excess of bainite and pearlite (black).

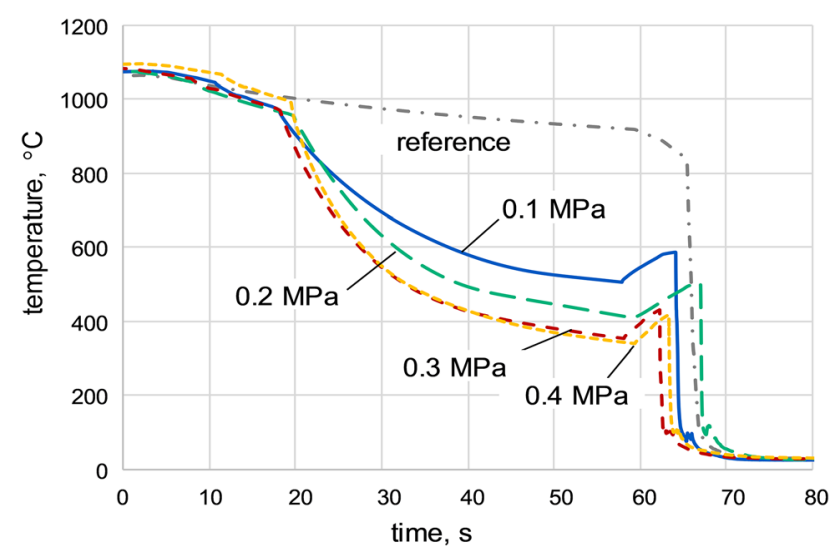

Fig. 6 Time-temperature profiles for varied air pressures (reference - center of blank without cooling; cooling distance tubeto-sheet $5 \mathrm{~mm}$, cooling time $40 \mathrm{~s}$ - experiments no. 1-4 in Table 4)

\subsection{Microstructure and Hardness Distribution for Increased Air Pressures During Pre-cooling}

Application of air pressures of more than $0.1 \mathrm{MPa}$ resulted in a convex form of the hardness profile (cf. Fig. 9). At pressures of $0.3 \mathrm{MPa}$ and $0.4 \mathrm{MPa}$, this convexity transforms to a plateau reaching levels of 435 HV5 and 440 HV5, respectively. The higher the pressure, the smaller the deviation of hardness values between different samples (about \pm 10 HV5 for pressures of 0.3 and $0.4 \mathrm{MPa}$ ). The mean hardness values are given in Table 7. Remarkably, the zone with minimal hardness (260-270 HV5) grows in diameter from 17 to $36 \mathrm{~mm}$ $( \pm 2 \mathrm{~mm})$ with increasing air pressures. It can be assumed that this softened annular-shaped section of the material is caused due to heat conduction between the pre-cooled and the non-precooled sheet areas. This effect can be exploited in case the

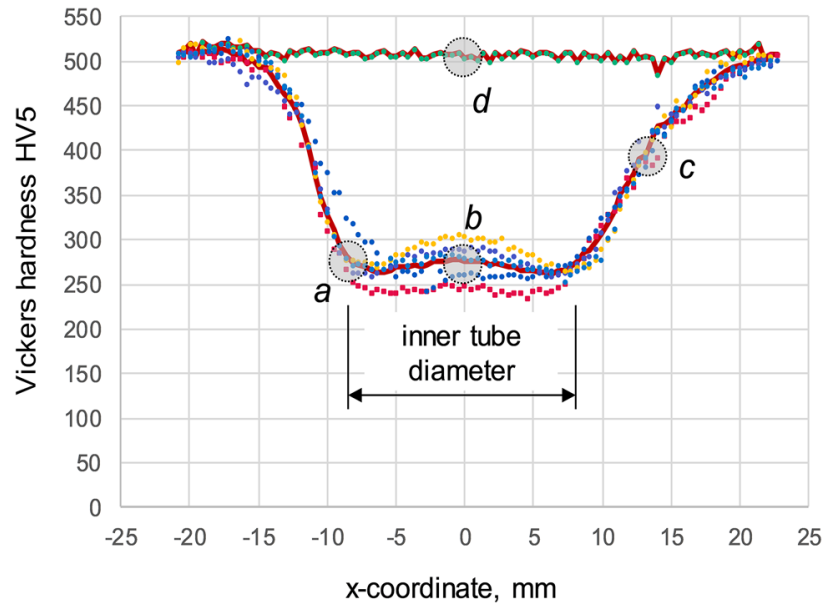

Fig. 7 Hardness profile in pre-cooled zones and for non-pre-cooled reference positions (upper green line); mean values of five different samples (experiment no. 1 in Table 4). The corresponding microstructures at positions " $a$ " to " $d$ " are depicted in Fig. 8

Table 5 Influence of the air pressure on the temperature in the center of the pre-cooling zone at the end of the precooling with compressed air

\begin{tabular}{lccc}
\hline Air pressure, MPa & Temperature*, ${ }^{\circ} \mathbf{C}$ & Mean cooling rate during pre-cooling, $\mathbf{K} / \mathbf{s}$ & Cooling rate $\left(\mathbf{8 0 0 - 5 0 0}{ }^{\circ} \mathbf{C}\right), \mathbf{K} / \mathbf{s}$ \\
\hline 0.1 & 505 & 12.0 & 9.1 \\
0.2 & 430 & 13.7 & 19.6 \\
0.3 & 345 & 15.9 & 25.4 \\
0.4 & 330 & 16.3 & 27.3 \\
$*$ when cooling from $980{ }^{\circ} \mathrm{C}$ & & & \\
\hline
\end{tabular}

Table 6 Mechanical properties of the tensile samples with pre-cooled soft zone (cooling time 40 s, tube-to-sheet distance $5 \mathrm{~mm})$

Air pressure, MPa

Ultimate tensile strength, MPa

$0.2 \%$ offset yield stress, MPa

0.1

0.2 

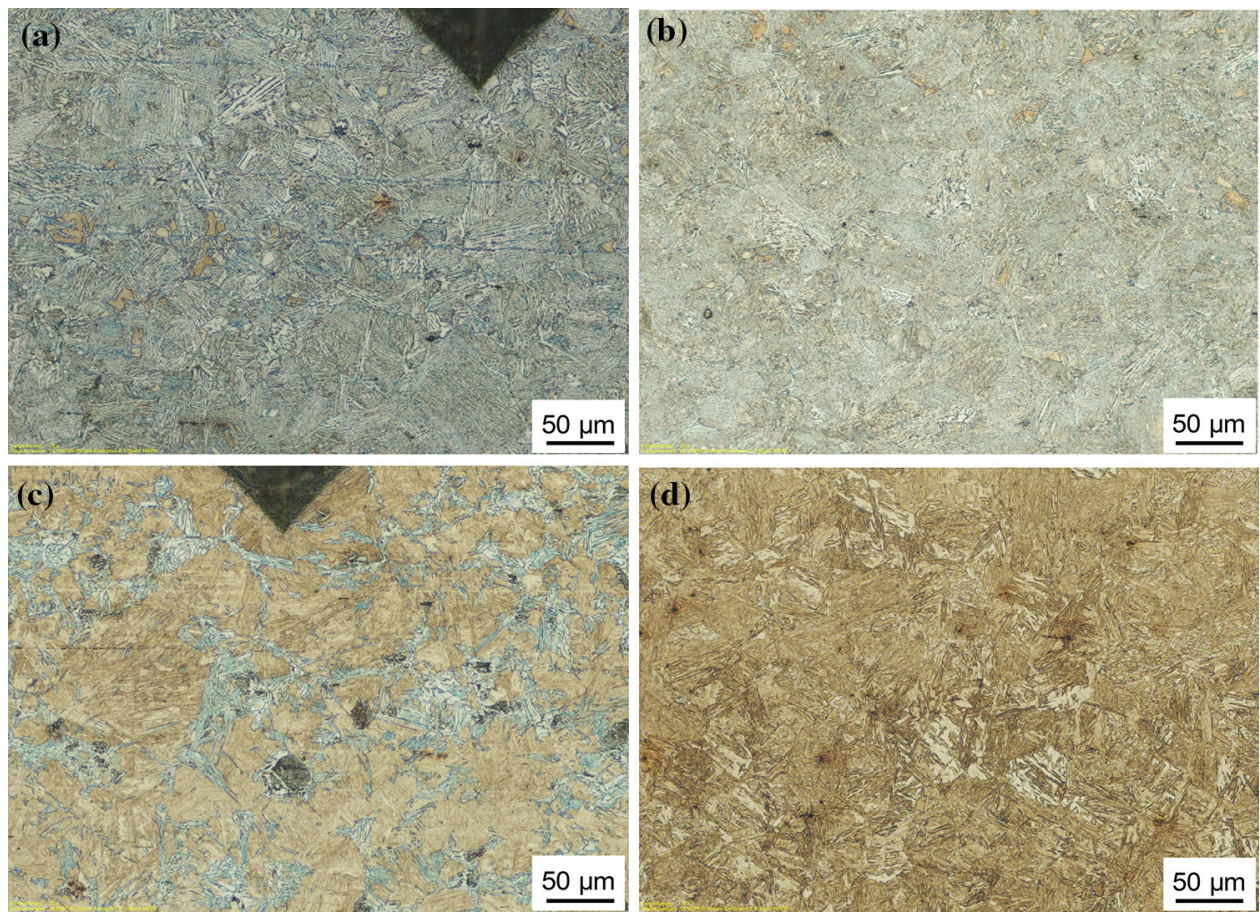

Fig. 8 Microstructure in different areas of the locally pre-cooled blank of experiment no. 1 from Table 4: a-area with lowest hardness (pos. " $a$ " in Fig. 7), b-area in the center of the air cooled zone (pos. " $b$ " in Fig. 7), c- transition area (pos. " $c$ " in Fig. 7), d- non-pre-cooled center of the blank (pos. "4" in Fig. 2 and pos. " $d$ " in Fig. 7); martensite—brown, bainite—grey, pearlite—black

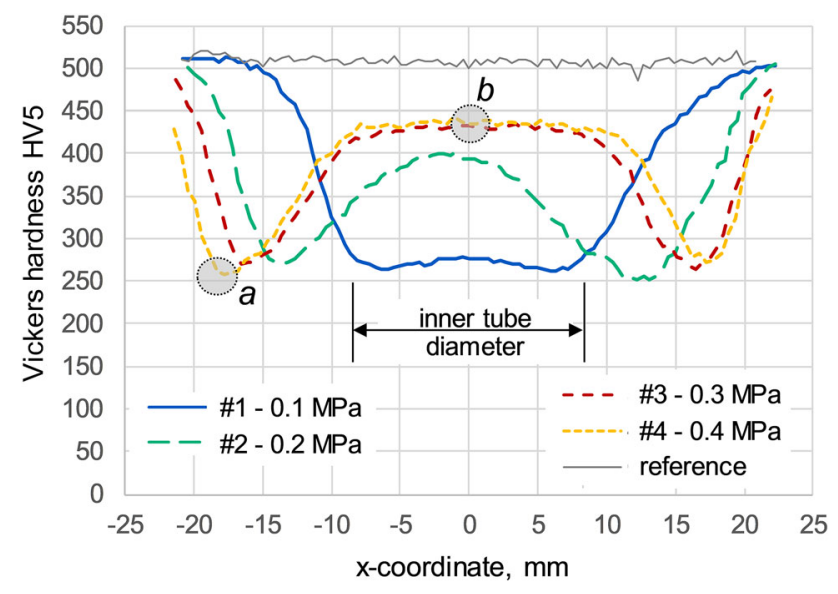

Fig. 9 Hardness profiles across the pre-cooled softened zones after cooling at different air pressures (experiments no. 1-4 in Table 4, reference - center of the blank without pre-cooling). The microstructures in areas marked " $a$ " and " $b$ " are depicted in Fig. 10

treated zones are to be punched-out later. The diameter of the softened circular zone can be varied easily by changing the air pressures without modifying the feeding and tubular cooling device. The small changes of the minimal hardness are reflected in the moderate variations of tensile strength (up to 6\%) for different air pressure levels (cf. Table 6).

The width of the transition zone between soft and fully hardened material sections is not sensitive to the air cooling parameters and ranges from $5 \mathrm{~mm}$ to $10 \mathrm{~mm}$, which is significantly lower than reported (Feu16, Hie16). This value also depends on the contact conditions between the tabular cooling device and the treated blank. Thus, it appears reasonable to assume that the diameter of the pre-cooled zone could be decreased further.

The microstructure of a specimen pre-cooled at an air pressure of $0.4 \mathrm{MPa}$ shows a mostly bainitic microstructure (Fig. 10a) in the area of minimal hardness (pos. " $a$ " in Fig. 9), while martensite dominates in the central area (pos. " $b$," Fig. 9).

\subsection{Influence of Tube-to-Sheet Distance and Duration of Pre-cooling}

Increasing the tube-to-sheet distance has no pronounced influence on the hardness values (Fig. 11). The maximum difference in the center for samples pre-cooled with a distance of 5 and $20 \mathrm{~mm}$ was only to $30 \mathrm{HV} 5$; with decreasing distance, the hardness in the center increases.

Decreasing of the pre-cooling time from 40 to $30 \mathrm{~s}$ (Fig. 11) results in an increase in the minimal hardness of about 20 HV5, while the diameter of circular softened area drops from 28 to $23 \mathrm{~mm}$. Hence, decreasing the cooling time is another parameter to control the size of a softened zone. In addition, this provides an opportunity to decrease the total cooling time.

\subsection{Two-Step Pre-cooling}

In the second set of the experiments, a two-step cooling setup was used with a flow rate in the first phase of 38 and $58 \mathrm{l}$ / $\mathrm{min}$ in the second. The time of each phase was set to 10 or $15 \mathrm{~s}$ (no. 8-10 in Table 4). The hardness distributions in the precooled areas for three different parameter combinations are depicted in Fig. 12. It is apparent that the shortest pre-cooling time of $20 \mathrm{~s}$ results in the highest observed hardness level of 
Table 7 Effect of air pressure used in pre-cooling on hardness values and diameter of the zones from Fig. 9

\begin{tabular}{lccccc}
$\begin{array}{l}\text { Air } \\
\text { pressure, } \\
\text { MPa }\end{array}$ & $\begin{array}{c}\text { Hardness in the pre- } \\
\text { cooled center, HV5 }\end{array}$ & $\begin{array}{c}\text { Diameter of the } \\
\text { plateau, } \mathbf{m m}\end{array}$ & $\begin{array}{c}\text { Minimal value of } \\
\text { hardness, HV5 }\end{array}$ & $\begin{array}{c}\text { Diameter of minimum value } \\
\text { hardness zone, mm }\end{array}$ & $\begin{array}{c}\text { Diameter of cooling } \\
\text { affected zone, mm }\end{array}$ \\
\hline 0.1 & 275 & 17 & 260 & 17 & 35 \\
0.2 & 400 & $\ldots$ & 265 & 26 & 41 \\
0.3 & 435 & 15 & 270 & 33 & 44 \\
0.4 & 17 & 270 & 36 \\
\hline
\end{tabular}
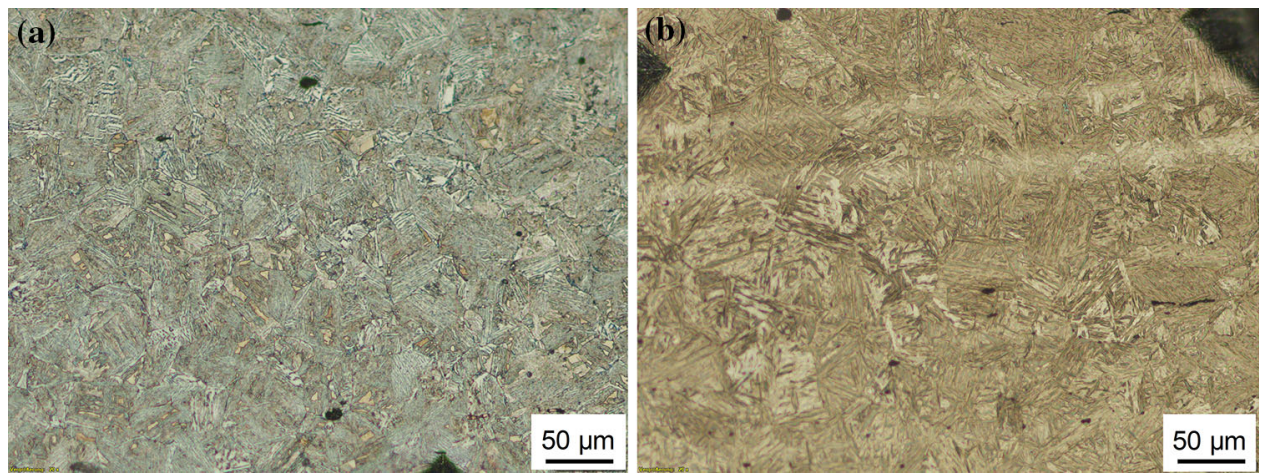

Fig. 10 Microstructure in different areas of the pre-cooled and quenched blank, experiment no. 4 from Table 4: a-zone with minimal hardness (pos. " $a$ " in Fig.9), b—zone in the center of pre-cooled area (pos. " $b$ " in Fig. 9); martensite— brown, bainite—grey, pearlite—black

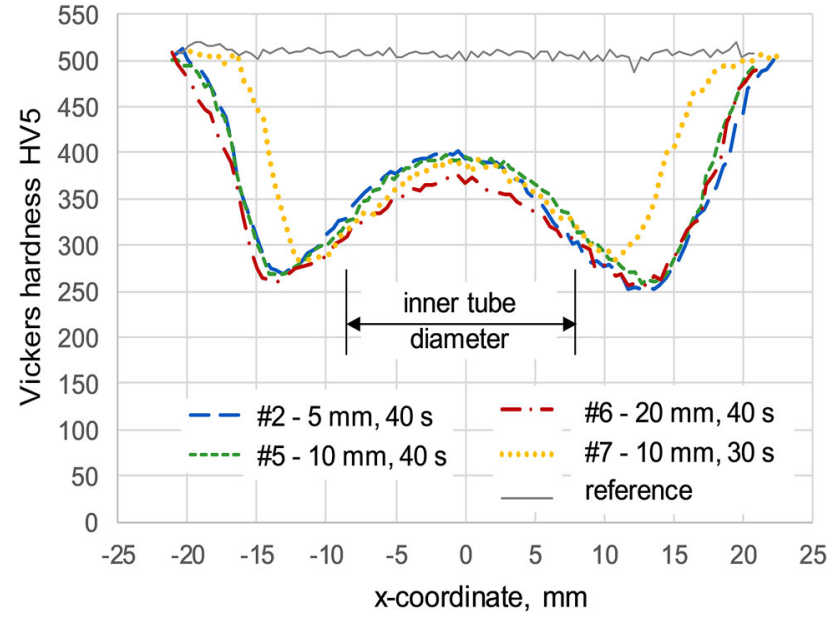

Fig. 11 Hardness profiles in pre-cooled softened zones after cooling at air pressures of $0.2 \mathrm{MPa}$ and varied tube-to-sheet distances and times of cooling, experiments no. 2, 5-7 in Table 4 (reference - center of blank, without pre-cooling)

about $350 \mathrm{HV} 5$, whereas at 25 and $30 \mathrm{~s}$ a hardness of $300 \mathrm{HV} 5$ was obtained in the center. Moreover, the soft zone after a treatment of $30 \mathrm{~s}$ is broadened.

\subsection{Integration of Pre-cooling into a Hot Stamping Process}

The results obtained for processing pre-cooled blanks by hot stamping with water cooled dies instead of water quenching are depicted in Fig. 13 for the tubular cooling and an alternative cooling where an additional point jet nozzle (PJ) was mounted on the inner tube. As expected, the reference hardness of 470 HV5 is somewhat lower as compared to the reference hardness

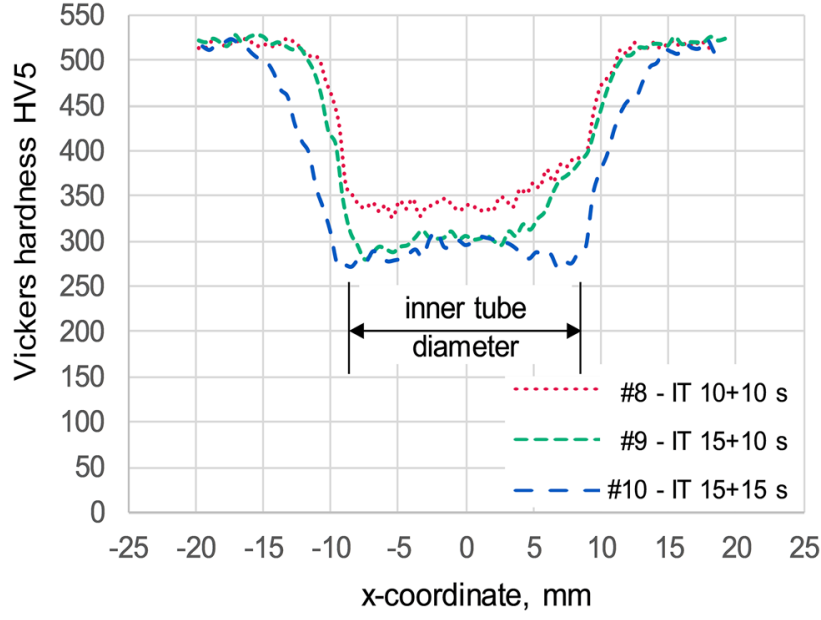

Fig. 12 Hardness profiles after two-step inner tube air pre-cooling with a final quenching in a water bath-experiments no. 8-10 in Table 4

of 500 HV5 determined for water quenched sheets. Similar to the observations made when water quenching, a process of $30 \mathrm{~s}$ has a slight tendency toward forming a convex HV-curve in the center as compared to a process of $25 \mathrm{~s}$. With a diameter of $25 \mathrm{~mm}$, the softened zone is even more pronounced than the one obtained by water quenching.

The lowest hardness level of approximately 260 HV5 was achieved by the application of a small point jet nozzle as the closing of the inner tube. The diameter of the hardness plateau is approximately $14 \mathrm{~mm}$, while the overall diameters of the affected zones are 26 and $34 \mathrm{~mm}$ for cooling times of 25 and $30 \mathrm{~s}$, respectively. Hence, the application of small point jet 


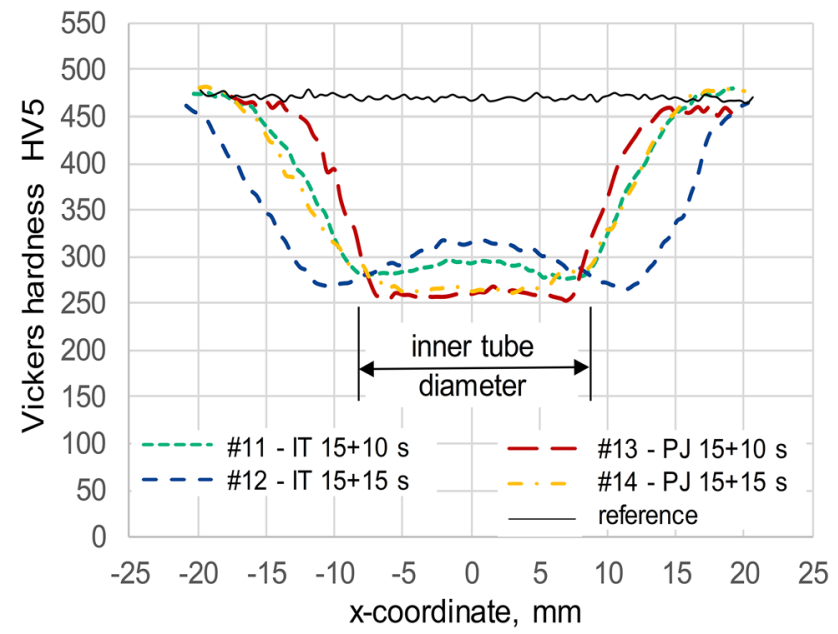

Fig. 13 Hardness profiles after a two-step air pre-cooling and hot stamping-experiments no. 11-14 in Table 4: IT-application of inner tube pre-cooling; $\mathrm{PJ}$-application of a point jet nozzle; reference-non-pre-cooled material

nozzles allows providing a constant low level of hardness during hot stamping, which can be varied easily by adapting the cooling time.

\section{Summary and Conclusions}

In order to obtain soft local zones suited for mechanical joining after hot stamping, a multi-step cooling process is proposed. In the first stage-while the main blank remains austenitized - the later soft local zones are pre-cooled by compressed air prior to the actual hot stamping in order to obtain a bainitic microstructure. Subsequently, hot stamping can be carried out to generate a martensitic microstructure in the not pre-cooled material sections. To realize the process, a tubular air-cooling device was designed in combination with a sheet insulation containment while applying the local precooling with compressed air.

Varying the air pressure during pre-cooling in the range from 0.1 to $0.4 \mathrm{MPa}$ resulted in a temperature in the center of cooling between 505 and $330{ }^{\circ} \mathrm{C}$. A pre-cooling treatment at $0.1 \mathrm{MPa}$ air pressure for $40 \mathrm{~s}$ allowed obtaining a significantly softened bainitic zone (260-270 HV5) with a diameter approximately equal to the diameter of the outer exhaust tube. The hardness of the material outside the pre-cooled sections was unaffected with constant values of about 500 HV5. Increasing the air pressure up to $0.4 \mathrm{MPa}$ increased the diameter of the zone with a minimal hardness from 17 to $36 \mathrm{~mm}$, while the hardness in the center of the pre-cooled zone was up to $440 \mathrm{HV} 5$. The transition zone between soft and hardened had a length of 5-10 $\mathrm{mm}$. Increasing the tube-to-sheet distance from 5 to $20 \mathrm{~mm}$ let to only marginal growth of hardness by about $30 \mathrm{HV}$. Changing the air cooling time from 40 to $30 \mathrm{~s}$ resulted in a slight increase in minimal hardness by $\approx 20 \mathrm{HV} 5$, but the diameter of the circular soft zone dropped by $18 \%$. Modification of the tubular cooling device and application of a two-stage cooling with an initial air pressure of $0.05 \mathrm{MPa}$ and a subsequent pressure of $0.1 \mathrm{MPa}$ allowed decreasing the cooling time to 20-25 s with a resulting hardness level in the softened zone of approximately 300 HV5.

Trials with an industrial press demonstrated that the approach can applied to industry relevant conditions. In this case, pre-cooling followed by hot stamping with a water cooled tool resulted in lowest hardness of about $260 \mathrm{HV} 5$, which is also substantial decrease as compared to the hardness value of 470 H5 determined for the non-pre-cooled sections of the material. The size of the soft zone and cooling-affected zone can be varied by changing the air pressure and the cooling time without modification of the presented tubular air-cooling device.

The proposed process chain with pre-cooling prior when hot stamping to obtain soft local zones allows to use conventional furnaces and hot stamping tools. In addition, it does not contribute to distortion of the final parts as the process is applied prior to hot-stamping. The considered type of aircooling devices can be integrated into production lines and used in parallel in order to provide a high productivity. Application of air pre-cooling instead of water-air spray cooling allows to avoid vapor formation as well as issues with oxidation of the treated zones.

\section{Acknowledgments}

Open Access funding provided by Projekt DEAL. The presented data were obtained within the project "Production of areas with reduced strength in press-hardened components by means of a tempering station," Project Number 313453754, granted by the German Research Foundation (DFG). The authors are thankful for the financial support.

\section{Open Access}

This article is licensed under a Creative Commons Attribution 4.0 International License, which permits use, sharing, adaptation, distribution and reproduction in any medium or format, as long as you give appropriate credit to the original author(s) and the source, provide a link to the Creative Commons licence, and indicate if changes were made. The images or other third party material in this article are included in the article's Creative Commons licence, unless indicated otherwise in a credit line to the material. If material is not included in the article's Creative Commons licence and your intended use is not permitted by statutory regulation or exceeds the permitted use, you will need to obtain permission directly from the copyright holder. To view a copy of this licence, visit http://creativecommons.org/licenses/by/4.0/.

\section{References}

1. H. Karbasian and A.E. Tekkaya, A Review on Hot Stamping, J. Mater. Process. Technol., 2010, 210, p 2103-2118

2. C. Löbe, O. Hering, L. Hiegemann, and E. Tekkaya, Setting Mechanical properties of High Strength Steels for Rapid Hot Forming Processes, Materials, 2016, 9, p 229. https://doi.org/10.3390/ma9040 229

3. K. Mori, B.F. Bariani, B.-A. Behrens, A. Brosius, M. Merklein, and J. Yanagimoto, Hot Stamping of Ultra-High Strength Steel Parts, CIRP Ann., 2017, 66(2), p 755-777

4. Tailored Tempering (Tailored Tempering), Digital Engineering Magazine, 2014, 02, p 24-25 (in German) 
5. J. Shi, in Investigation of the Effects of Heating and Quenching on the Mechanical Properties and Microstructure of 22MnB5 Steel Sheets, 2018, Electronic Theses and Dissertations, 7444. https://scholar.uwind sor.ca/etd/7444

6. B.-A. Behrens, C.M. Gaebel, J. Moritz, and J. Schrödter, Hot Stamping of Load Adjusted Structural Parts, Proc. Eng., 2014, 81, p 1756-1761

7. M. Glatzer, T. Stöhr, M. Merklein, S. Sikora, K. Lamprecht, G. Deinzer, Einfluss unterschiedlicher Wärmebehandlungsrouten auf die Robustheit der mechanischen Eigenschaften des Stahls 22MnB5 (Influence of different heat treatment routes onto robustness of mechanical properties of steel 22MnB5) 4, in Erlanger Workshop Warmblechumformung, DFG ortsverteilte Forschergruppe 552, 11. Nov, 2009, (Erlangen, DE), (Meisenbach), p. 85-105 (in German)

8. F.-J. Lenze, J. Banik, S. Sikora, T. Gerber, Further development of manganese boron steels for the lightweight design of body in white structures, in IDDRG: International Deep Drawing Research Group Conference, Tools and Technologies for the Processing of Ultra High Strength Steels, Conf Proc, May 31-Jun 2, 2010 (Graz, AT), (TU Graz), p. 17-26

9. L.O. Wolf, F. Nürnberger, D. Rodman, and H.J. Maier, 1-Step "Quenching and Partitioning" of the Press-Hardening Steel 22MnB5, Steel Res. Int., 2017, 88(6), p 1600307

10. L.O. Wolf, J.-P. Cordebois, D. Rodman, F. Nürnberger, and H.J. Maier, Effect of Different Intercritical Annealing Treatments Without and With Overaging on the Mechanical Material Behavior, Steel Res. Int., 2018, 89(10), p 1800196

11. L.O. Wolf, F. Nürnberger, D. Rodman, and H.J. Maier, The Effect of Intercritical Annealing on the Microstructure and Mechanical Properties of Ferritic-Martensitic Two-Phase Steels, Steel Res. Int., 2017, $\mathbf{8 8}(2)$, p 271-280

12. M. Maikranz-Valentin, U. Weidig, U. Schoof, H.-H. Becker, and K. Steinhoff, Components with Optimised Properties due to Advanced Thermo-Mechanical Process Strategies in Hot Sheet Metal Forming, Steel Res. Int., 2008, 79(2), p 92-97

13. T. Stöhr, J. Lechler, M. Merklein, Investigations on different strategies for influencing the microstructural properties with respect to partial hot stamping, in 2nd International Conference on Hot Sheet Metal Forming of High-Performance Steel, Jun 15-17, 2009 (Lulea, SE) (Verlag Wissenschaftliche Scripten), p. 273-281

14. B.-A. Behrens, A. Chugreev, M. Jalanesh, K. Wölki, F. Bohne, Parametrisation of a numerical model for a partial heating strategy used to evaluate a masking concept of a hot stamping process, Metal 2019, in 28th International Conference of Metallurgy and Materials, p. 320 325

15. M. Merklein, J. Lechler, and T. Stoehr, Investigations on the Thermal Behavior of Ultra High Strength Boron Manganese Steels Within Hot Stamping, Int. J. Mater. Form., 2009, 2(259), p 259-262

16. F. Zimmermann, W. Volk, J. Spörer, M. Pfestorf, Aktuelle Anwendungen im Bereich der Warmumformung höchstfester Stahlgüten im Karosseriebau und zukünftige Trends (Actual applications in the field of hot deformation of high strength steel products in the car body construction and future trends). 6. Erlanger Workshop Warmblechumformung, DFG ortsverteilte Forschergruppe 552, 17. Nov, 2011 (Erlangen, DE), Meisenbach, p. 81-94 (in German)

17. T. Marten, J. Niewel, and T. Tröster, Investigation on Alternative Heating Concepts for the Hot Sheet Metal Forming, HTM, 2011, 66, p 309-315

18. W. Liang, L. Wang, Y. Liu, Y. Wang, and Y. Zhang, Hot Stamping Parts with Tailored Properties by Local Resistance Heating, Procedia Eng., 2014, 81, p 1731-1736
19. A. Andreiev, O. Grydin, and M. Schaper, Evolution of Microstructure and Properties of Steel 22MnB5 Due to Short Austenitization with Subsequent Quenching, Steel Res. Int., 2016, 87(12), p 1733-1741

20. M.J. Holzweissig, J. Lackmann, S. Konrad, M. Schaper, and T. Niendorf, Influence of Short Austenitization Treatments on the Mechanical Properties of Low-Alloy Steels for Hot Forming Applications, Metall. Mater. Trans. A, 2015, 46, p 3199-3207

21. O. Grydin, A. Andreiev, M.J. Holzweißig, C.J. Rüsing, K. Duschik, Y. Frolov, and M. Schaper, Shot Austenitization Treatment with Subsequent Press Hardening: Correlation Between Prozess Parameters, Microstructure and Mechanical Properties, Mater. Sci. Eng., A, 2019, 749, p 176-195

22. C. Hielscher, S. Horn, Werneke, C. Buse, Herstellung von gradierten Bauteileigenschaften beim Presshärten durch gezielte Zwischenkühlung, 11. Erlanger Workshop Warmblechumformung, 17 Nov, 2016 (Erlangen, DE), Meisenbach, p. 77-92 (in German)

23. H. Lehmann, P. Feuser, Realisierung von "Tailored Properties" an pressgehärteten Bauteilen mittels "Thermischem Printing", 11. Erlanger Workshop Warmblechumformung, 17 Nov, 2016 (Erlangen, DE), Meisenbach, p. 63-75 (in German)

24. M. Merklein, M. Wieland, M. Lechner, S. Bruschi, and A. Ghiotti, Hot Stamping of Boron Steel Sheets with Tailored Properties: A Review, $J$. Mater. Process. Technol., 2016, 228, p 11-24

25. L. Galdos, E. Sanz de Argandona, R. Ortubay, Towards the Generation of Taylored Tempered Components: Concept Definition and Process Parameters Optimization, in IDDRG: International Deep Drawing Research Group Conf., June 2 - 5, 2013 (Zurich, Switzerland) Conf. Proc. CD ROM, Institute of Virtual Manufacturing (ETH Zurich), p. 425-430

26. M. Diekamp, S. Hübner, F. Nürnberger, M. Schaper, B.-A. Behrens, and F.-W. Bach, Prozessoptimiertes Presshärten Mittels Sprühkühlung-Prozessintegrierte Wärmebehandlung von Blechen des Werkstoffes 22MnB5, HTM J. Heat Treat. Mater, 2011, 6, p 316-322

27. F. Nürnberger, M. Diekamp, J. Moritz, L. Wolf, S. Hübner, B.-A. Behrens, Spray Cooling of Early Extracted Hot Stamped Parts, in TMS2014 Annual Meeting Supplemental Proc., Annual Meeting; 143rd, Minerals, Metals and Materials Society, 2014 (San Diego, CA) (Wiley, New York) p. 983-990

28. M. Merklein, T. Stöhr, T. Svec, M. Wieland, Funktionsoptimierte Strukturbauteile im Presshärtprozess (Functional Optimized Structural Componenets in Press Hardening), Lightweight Design, 2010, 3(5), Vieweg+Teubner Verlag, pp. 52-58

29. M. Spittel, T. Spittel, SpringerMaterials, Steel symbol/number: $22 \mathrm{MnB} 5 / 1.5528$, Landolt-Börnstein - Group VIII Advanced Materials and Technologies 2C1, 2009. https://materials.springer.com/lb/docs/s m_lbs_978-3-540-44760-3_146

30. M. Naderi, L. Durrenberger, A. Molinari, and W. Bleck, Constitutive Relationship for 22MnB5 Boron Steel Deformed Isothermally at High Temperatures, Mater. Sci. Eng., 2008, 478, p 130-139

31. H. Liu, J. Yu, and H. Zhao, Microstructure and Mechanical Properties of 22MnB5 Steel with Different cooling Method, Appl. Mech. Mater., 2013, 331, p 555-558

32. H. Güler, R. Ertan, and R. Özcan, Influence of Heat Treatment Parameters on the Microstructure and Mechanical Properties of BoronAlloyed Steels, Mater. Test., 2012, 54(9), p 619-624

Publisher's Note Springer Nature remains neutral with regard to jurisdictional claims in published maps and institutional affiliations. 